\title{
High-Pressure Synthesis of MgNi Intermetallic Compound and Its Thermal Stability
}

\author{
Yasutaka Kamata ${ }^{1, * 1}$, Riki Kataoka ${ }^{1, * 1}$, Daisuke $\mathrm{Kyoi}^{2, * 2}$, \\ Atsunori Kamegawa ${ }^{1}$ and Masuo Okada ${ }^{1}$ \\ ${ }^{1}$ Department of Materials Science, Graduate School of Engineering, Tohoku University, Sendai 980-8579, Japan \\ ${ }^{2}$ IMR, Tohoku University, Sendai 980-8577, Japan
}

\begin{abstract}
A novel intermetallic compound of MgNi was synthesized from amorphous MgNi by high pressure technique. Crystal structure, thermal stability and hydrogenation property of the compound were studied. The crystallized MgNi was synthesized at $573 \mathrm{~K}$ for $2 \mathrm{~h}$ under the pressure of more than $5 \mathrm{GPa}$, and was found to exhibit a CuTi-type structure with lattice parameters of $a=0.2997(1) \mathrm{nm}, c=0.3166(2) \mathrm{nm}$. The MgNi was decomposed into $\mathrm{Mg}_{2} \mathrm{Ni}$ and amorphous phase at $575 \mathrm{~K}$ and decomposed into $\mathrm{Mg}_{2} \mathrm{Ni}$ and $\mathrm{MgNi}_{2}$ over $682 \mathrm{~K}$. Moreover the $\mathrm{MgNi}$ was hydrogenated into novel hydride with a CsCl-type structure at $355 \mathrm{~K}$ under $2 \mathrm{MPa}$ hydrogen. This novel hydride with a lattice parameter of $a=0.3215(1) \mathrm{nm}$ was decomposed into $\mathrm{Mg}_{2} \mathrm{Ni}$ and $\mathrm{MgNi}_{2}$ over $428 \mathrm{~K}$ under an $\mathrm{Ar}$ atmosphere. [doi:10.2320/matertrans.MBW200782]
\end{abstract}

(Received October 18, 2007; Accepted December 14, 2007; Published February 6, 2008)

Keywords: hydrogen storage alloy, high-pressure, magnesium

\section{Introduction}

Mg-based alloys and their hydrides have been extensively studied because of their promising applications as hydrogen storage media. However, it is well known that the Mg-based hydrides need high operating temperatures, especially for dehydrogenation. To improve their hydrogenation and dehydrogenation properties, it is important to explore new Mg-based hydrides and intermetallic compounds.

For that purpose, high pressure synthesis is known to an effective method to explore novel compounds. In the field of hydrogen storage media, many new hydrides have been obtained by this technique. The high pressure synthesis can be mainly classified into two groups according to manner of pressure transmitting media, those are, gases media in autoclave, and solid ones such as anvil-type apparatus. For example, $\mathrm{CsMgH}_{3}$, ${ }^{1)} \mathrm{LaMg}_{2} \mathrm{H}_{7}{ }^{2)}$ and $\mathrm{CeMg}_{2} \mathrm{H}_{7}{ }^{2)}$ have been prepared under a high pressure of about $10 \mathrm{MPa}$ by using the autoclave apparatus. On the other hand, $\mathrm{Mg}_{3} \mathrm{MnH}_{7}{ }^{3)}$ and $\mathrm{Sr}_{6} \mathrm{Mg}_{7} \mathrm{H}_{26}{ }^{4)}$ and so on, were reported to be synthesized under a high pressure up to GPa range using anvil-type apparatus. In our previous work, $\mathrm{Mg}_{2} \mathrm{Ni}_{3} \mathrm{H}_{3.4}$, ,6) $\mathrm{Mg}_{3}$ $\mathrm{MnH}_{y}{ }^{7)} \mathrm{MgY}_{2} \mathrm{H}_{8}{ }^{7-10)} \mathrm{Mg}_{54} \mathrm{Cu}_{17}{ }^{11)}$ and $\mathrm{MgNi}_{2}$ high pressure phase $^{12)}$ have been obtained by using anvil-type apparatus.

$\mathrm{MgCu}^{11)}$ with a CsCl-type structure has been obtained by using anvil-type apparatus in our previous work. The crystal structure and chemical formula of $\mathrm{MgCu}$ are the same as that of $\mathrm{MgAg}$ and $\mathrm{MgAu}$ which are equilibrium phases obtained under ambient pressure while both $\mathrm{Ag}$ and $\mathrm{Au}$ are homologous elements with $\mathrm{Cu}$. There is a tendency that compounds which has homologous elements have similar crystal structure and chemical formula.

In Mg-10group system, $\mathrm{MgPd}$ and $\mathrm{MgPt}$ intermetallic compounds have $\mathrm{CsCl}$-type and $\mathrm{FeSi}$-type structure, respectively. On the other hand, $\left(\mathrm{Mg}_{1-x} \mathrm{Al}{ }_{x}\right) \mathrm{Ni}(x=0.3 \sim 0.5)$ prepared by mechanical alloying have $\mathrm{CsCl}$-type structure, ${ }^{13}$ ) however MgNi binary compound has not been reported. By

\footnotetext{
${ }^{* 1}$ Graduate Student, Tohoku University

${ }^{* 2} \mathrm{COE}$ fellow, Present address: Sasakura engineering Co., Ltd.
}

the way, amorphous $\mathrm{MgNi}$ phase has been synthesized by mechanical milling method. ${ }^{14)}$ So, there is a possibility to synthesize crystallized $\mathrm{MgNi}$ by high pressure technique.

In this work, we investigated novel $\mathrm{MgNi}$ compound and the possibility of hydrogenation of the compound. The crystal structure, thermal stability, hydrogenation property and hydrogen content of the newly found compounds are also investigated.

\section{Experimental Procedures}

Raw materials were $\mathrm{Mg}$ (99.9 mass\%) and $\mathrm{Ni}$ (99.9 mass\%) powders. $\mathrm{Mg}_{2} \mathrm{Ni}$ was prepared by sintering at $803 \mathrm{~K}$ for $5 \mathrm{~h}$ under $\mathrm{Ar}-3 \mathrm{~mol} \% \mathrm{H}_{2}$ atmosphere from mixture of $\mathrm{Mg}$ and $\mathrm{Ni}$ powders. Amorphous $\mathrm{MgNi}$ was obtained after $80 \mathrm{~h}$ of milling at $200 \mathrm{rpm}$ by mechanical alloying from $\mathrm{Mg}_{2} \mathrm{Ni}$ and $\mathrm{Ni}$ powders. The amorphous $\mathrm{MgNi}$ was used as a precursor and was pressed into a pellet. On the other hand, mixtures of $\mathrm{Mg}$ and $\mathrm{Ni}$ were also used as precursors. The pellet was put into a $\mathrm{BN}$ container, which is expected to work as electric insulator. The container was then put into a graphite tube heater, and placed into a pressure media made from pyrophyllite. All the manipulations of sample preparations were conducted in a glove box filled with an Ar gas. The high-pressure synthesis was carried out by using anvil-type apparatus. Samples were heated at 573-973 K for $2 \mathrm{~h}$ under 2-6 GPa and then quenched into ambient temperature and pressure. Phase identification was carried out by X-ray diffractometry (XRD). Then, lattice parameters were refined by CELL ${ }^{15)}$ program. Thermal stability of the samples was measured by differential scanning calorimeter (DSC) under an Ar atmosphere. Hydrogenation of the samples was also performed by DSC under $2 \mathrm{MPa}$ hydrogen. The hydrogen content of hydrides was measured by means of a fusion extraction analysis.

\section{Results and Discussion}

Figure 1 shows XRD patterns of an amorphous $\mathrm{MgNi}$ precursor and the $\mathrm{MgNi}$ samples prepared at $573 \mathrm{~K}$ and $673 \mathrm{~K}$ 


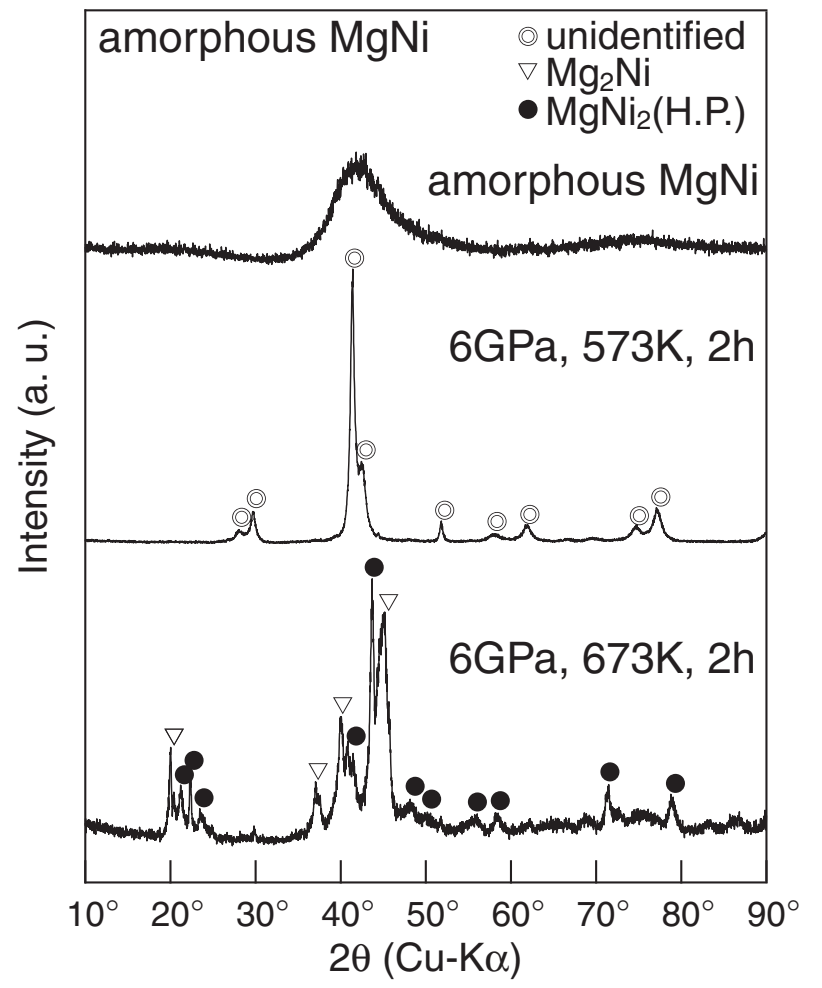

Fig. 1 XRD patterns of an amorphous $\mathrm{MgNi}$ precursor and the $\mathrm{MgNi}$ samples prepared at $573 \mathrm{~K}$ and $673 \mathrm{~K}$ for $2 \mathrm{~h}$ under $6 \mathrm{GPa}$.

for $2 \mathrm{~h}$ under $6 \mathrm{GPa}$. The halo pattern from amorphous phase was disappeared and unidentified phase was observed as an almost single phase for the sample prepared at $573 \mathrm{~K}$. However only identified phases such as $\mathrm{MgNi}_{2}$ high pressure phase and $\mathrm{Mg}_{2} \mathrm{Ni}$ were appeared for the sample prepared at $673 \mathrm{~K}$.

Figure 2 shows XRD patterns. A simulated pattern as a primitive tetragonal structure (CuTi-type; $P 4 / \mathrm{mmm}$, No. 123) is also shown in this figure. This pattern was similar to that of the sample prepared at $573 \mathrm{~K}$. So the novel phase was found to be $\mathrm{MgNi}$ as a high pressure phase and then the lattice parameters were estimated to be $a=0.2997(1) \mathrm{nm}, c=$ $0.3166(2) \mathrm{nm}$. The CuTi-type structure is similar to a CsCltype structure such as MgPd. The occupation of atoms in these crystal structures is similar each other. However the deference between $\mathrm{CuTi}$ and $\mathrm{CsCl}$ is their structure types of tetragonal or cubic. So the structure of $\mathrm{MgNi}$ is similar to that of $\mathrm{MgPd}$.

Figure 3 shows XRD patterns of the $\mathrm{MgNi}$ samples prepared at $573 \mathrm{~K}$ for $2 \mathrm{~h}$ under varying pressure of 4-6 $\mathrm{GPa}$. As a result, the $\mathrm{MgNi}$ was obtained above $5 \mathrm{GPa}$.

Figure 4 shows XRD patterns of the samples, which was used by precursor of $\mathrm{Mg}-50 \mathrm{~mol} \% \mathrm{Ni}$ mixture, prepared at 573-973 K for $2 \mathrm{~h}$ under $6 \mathrm{GPa}$. However, the MgNi was not obtained and only raw materials were observed. In addition, only identified phases were appeared for the samples prepared at $773 \mathrm{~K}$ and $973 \mathrm{~K}$. So in this synthesis condition novel phase was obtained by the use of only amorphous $\mathrm{MgNi}$ as a precursor.

To investigate thermal stability of novel $\mathrm{MgNi}$ compound, DSC measurement was performed under an Ar atmosphere. Figure 5 shows DSC curve of the MgNi. Two exothermic

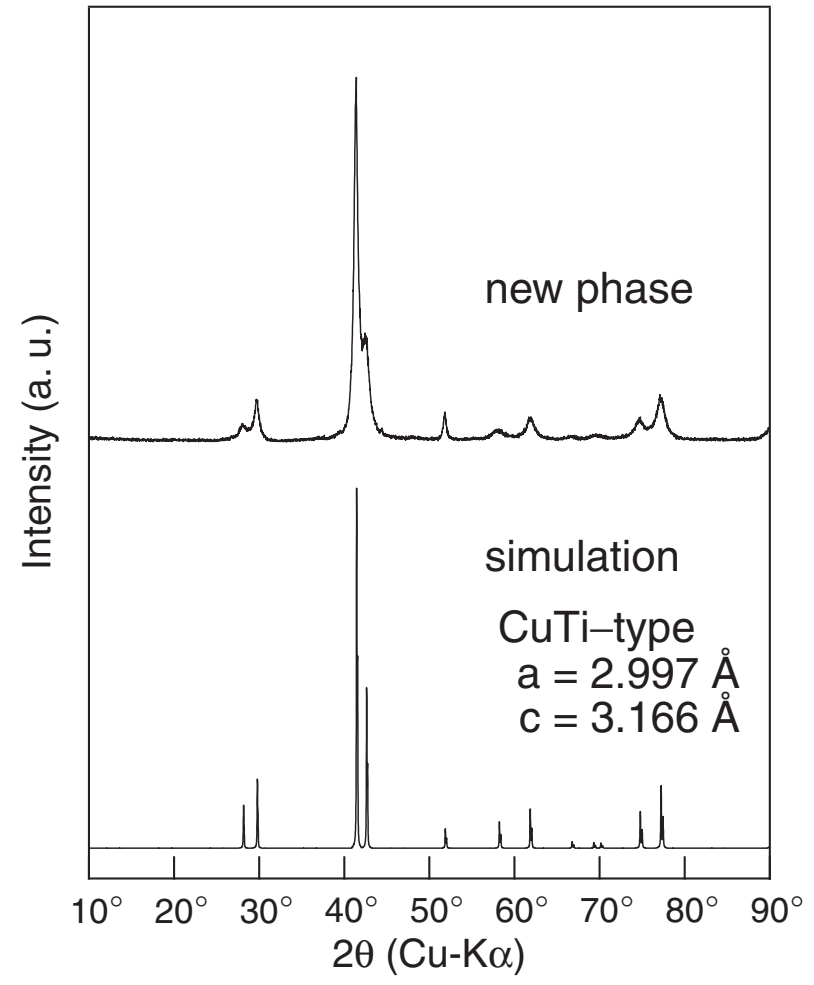

Fig. 2 XRD pattern of MgNi sample prepared at $573 \mathrm{~K}$ for $2 \mathrm{~h}$ under $6 \mathrm{GPa}$ and simulated pattern as a CuTi-type structure.

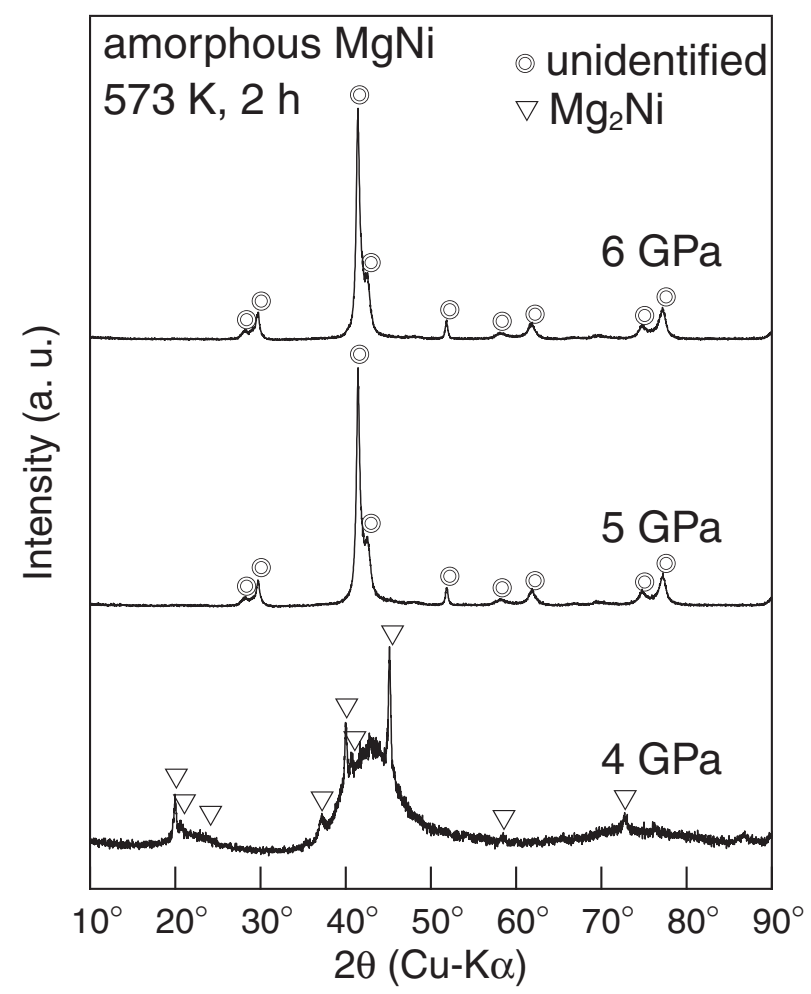

Fig. $3 \mathrm{XRD}$ patterns of $\mathrm{MgNi}$ samples prepared at $573 \mathrm{~K}$ for $2 \mathrm{~h}$ under 4-6 GPa.

peaks were observed at $575 \mathrm{~K}$ and $682 \mathrm{~K}$. From X-ray diffraction results after the DSC measurement, $\mathrm{MgNi}$ decomposed to $\mathrm{Mg}_{2} \mathrm{Ni}$ and amorphous phase at $575 \mathrm{~K}$, and $\mathrm{MgNi}_{2}$ appeared over $682 \mathrm{~K}$. 


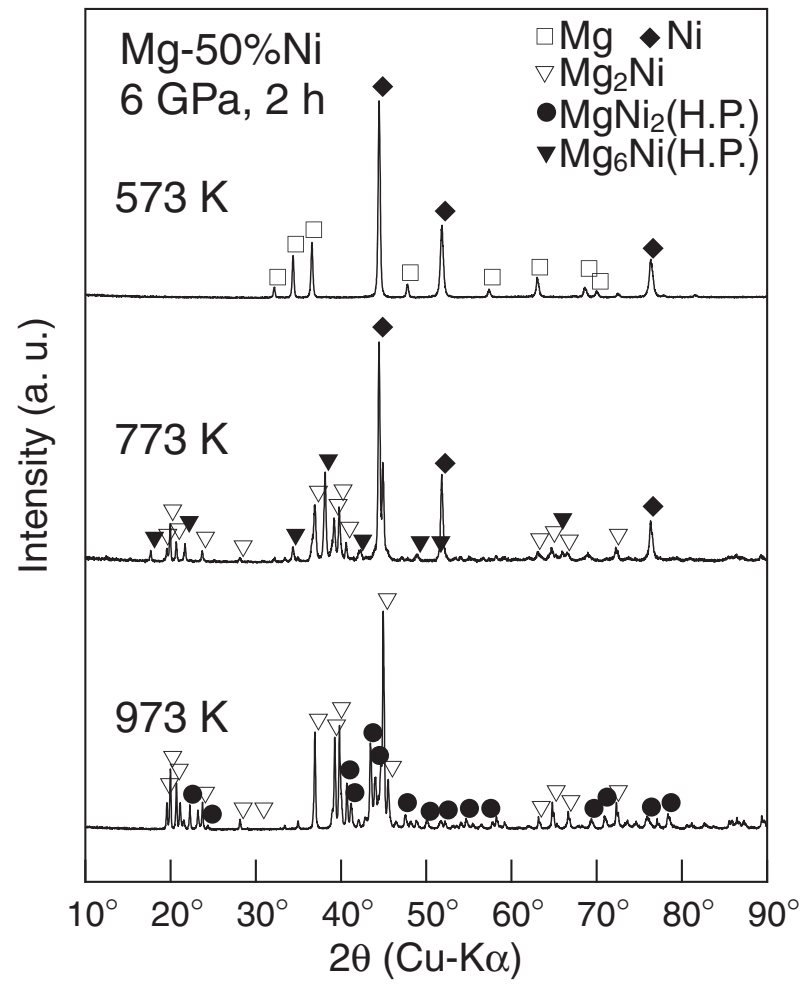

Fig. 4 XRD patterns of Mg-50 mol\% Ni samples prepared at 573-973 K for $2 \mathrm{~h}$ under $6 \mathrm{GPa}$.

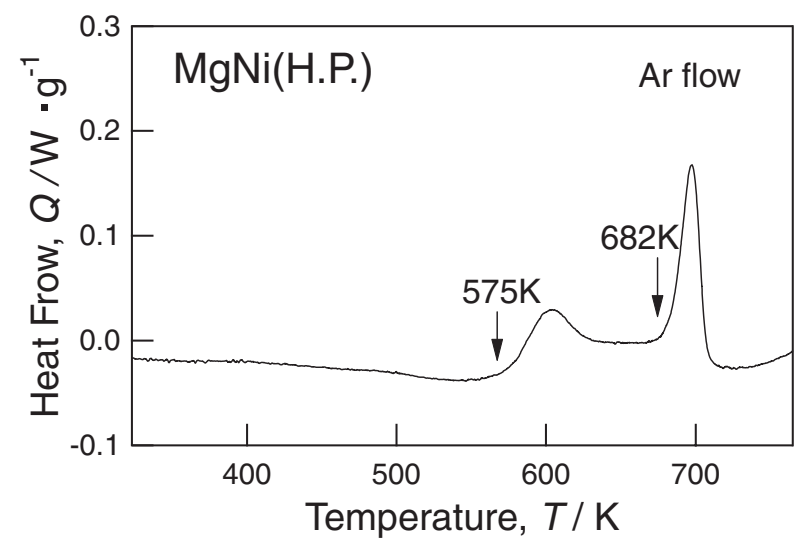

Fig. 5 DSC curve of MgNi under an Ar atmosphere.

To investigate hydrogenation property of the $\mathrm{MgNi}$, DSC measurement was performed under $2 \mathrm{MPa}$ hydrogen atmosphere (Fig. 6). An exothermic peak was observed at $355 \mathrm{~K}$. From X-ray diffraction results after the DSC measurement, the $\mathrm{MgNi}$ was disappeared and an unidentified phase was obtained as an almost single phase. Figure 7 shows XRD patterns of the unidentified phase and that of simulated primitive cubic structure (CsCl-type; $\mathrm{Pm}$-3m, No. 221). These patterns were similar each other. The hydrogen amount of the hydrogenated sample was estimated to be 1.89 mass\% by fusion analysis and the corresponding chemical formula of the novel phase can be expressed as $\mathrm{MgNiH}_{1.6}$.

Figure 8 shows DSC curve of the novel hydride measured under Ar atmosphere. An endothermic peak was observed at about $428 \mathrm{~K}$. From X-ray diffraction results after the DSC

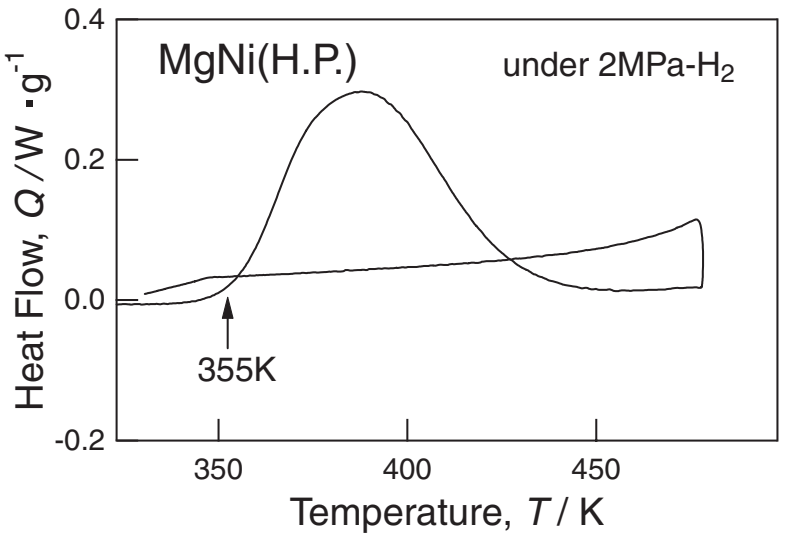

Fig. 6 DSC curve of MgNi under $2 \mathrm{MPa}$ hydrogen.

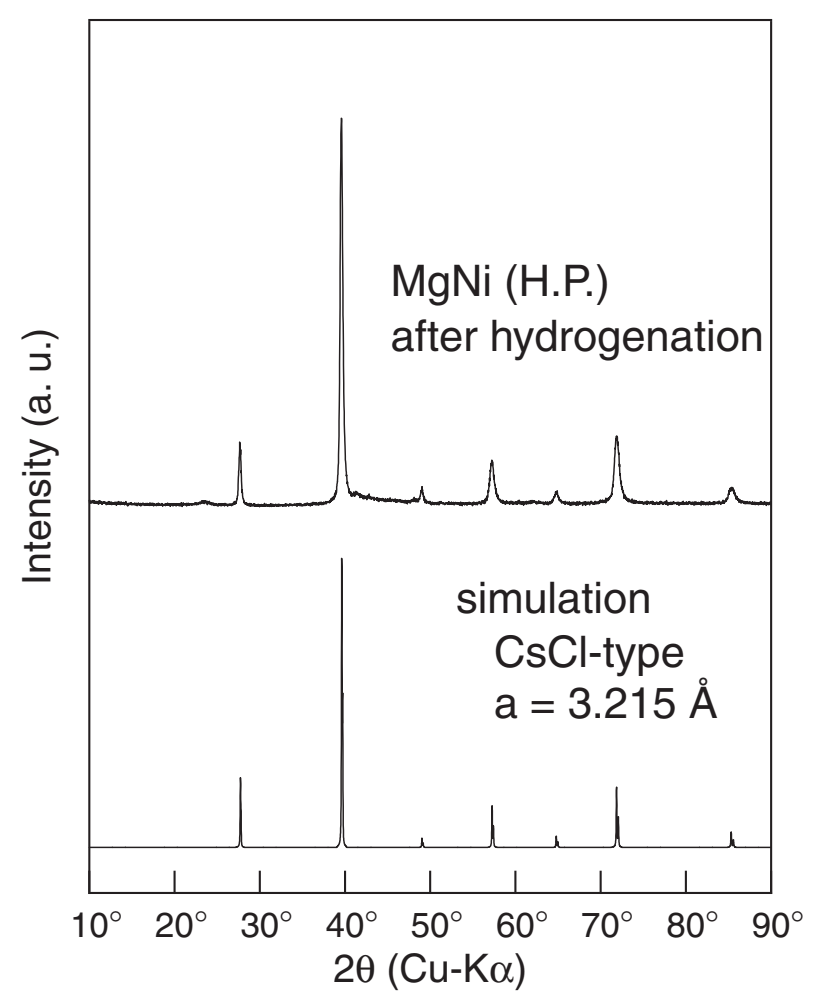

Fig. 7 XRD pattern of the sample after hydrogenation of $\mathrm{MgNi}$ and simulated pattern as a CsCl-type structure.

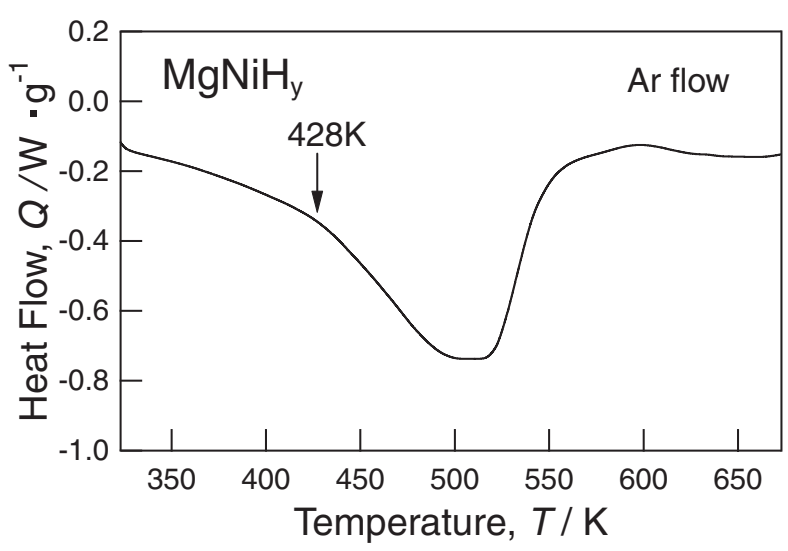

Fig. 8 DSC curve of $\mathrm{MgNiH}_{y}$ under an Ar atmosphere. 
measurement up to $670 \mathrm{~K}, \mathrm{Mg}_{2} \mathrm{Ni}$ and $\mathrm{MgNi}_{2}$ were observed. A decomposition with dehydrogenation would occur.

\section{Conclusion}

The novel intermetallic compound of $\mathrm{MgNi}$ is synthesized by high pressure technique at $573 \mathrm{~K}$ for $2 \mathrm{~h}$ under the pressure of more than $5 \mathrm{GPa}$. The novel phase is found to exhibit a CuTi-type structure (space group $P 4 / \mathrm{mmm}$, No. 123) with lattice parameters of $a=0.2997(1) \mathrm{nm}, c=0.3166(2) \mathrm{nm}$. The MgNi hydrogenated into novel hydride with a CsCl-type structure at $355 \mathrm{~K}$ under $2 \mathrm{MPa}$ hydrogen. This novel hydride with a lattice parameter of $a=0.3215(1) \mathrm{nm}$ was decomposed into $\mathrm{Mg}_{2} \mathrm{Ni}$ and $\mathrm{MgNi}_{2}$ over $428 \mathrm{~K}$ under an $\mathrm{Ar}$ atmosphere. Its hydrogen content is estimated to be 1.89 mass \% from fusion analysis and corresponding chemical formula is found to be $\mathrm{MgNiH}_{1.6}$.

\section{Acknowledgement}

This work has been supported in part by New Energy and Industrial Technology Development Organization (NEDO).

\section{REFERENCES}

1) B. Bertheville, P. Fischer and K. Yvon: J. Alloys Compd. 330-332 (2002) 152-156.

2) F. Gingl, K. Yvon, T. Vogt and A. Hewat: J. Alloys Compd. 253-254 (1999) 125-129.

3) M. Bortz, B. Bertheville, K. Yvon, E. A. Movlaev, V. N. Verbetsky and F. Fauth: J. Alloys Compd. 279 (1998) L8-L10.

4) B. Bertheville and K. Yvon: J. Alloys Compd. 288 (1999) 197-199.

5) H. Kakuta, A. Kamegawa, H. Takamura and M. Okada: Mater. Sci. Forum 350-351 (2000) 329-332.

6) H. Takamura, H. Kakuta, A. Kamegawa and M. Okada: J. Alloys Compd. 330-332 (2002) 157-161.

7) Y. Goto, H. Kakuta, A. Kamegawa, H. Takamura and M. Okada: Sci. Technol. Adv. Mater. 4 (2003) 333-338.

8) Y. Goto, A. Kamegawa, H. Takamura and M. Okada: Mater. Trans. 43 (2002) 2717-2720.

9) H. Takamura, Y. Goto, A. Kamegawa and M. Okada: Mater. Trans. 44 (2003) 583-588.

10) H. Takamura, Y. Goto, A. Kamegawa and M. Okada: Mater. Sci. Forum 419-422 (2003) 983-988.

11) H. Watanabe, Y. Goto, H. Kakuta, A. Kamegawa and M. Okada: Mater. Trans. 45 (2004) 1350-1354.

12) H. Kakuta: Ph. D. thesis, Tohoku University, 2000 (in Japanese).

13) S. Orimo, K. Ikeda and H. Fujii: J. Alloys Compd. 266 (1998) L1-L3.

14) Y. Q. Lei, Y. M. Wu, Q. M. Yang and Q. D. Wang: Z. Phys. Chem. 183 (1994) 379.

15) Y. Takaki, T. Taniguchi and K. Hori: J. Ceram. Soc. Jpn. Inter. Ed. 101 (1993) 373. 